\title{
Impact of transformational leadership on work performance, burnout and social loafing: a mediation model
}

\author{
Hira Khan ${ }^{1}$, Maryam Rehmat ${ }^{2,3^{*}}$ (]), Tahira Hassan Butt ${ }^{3}$, Saira Farooqi ${ }^{2,3}$ and Javaria Asim ${ }^{2,3}$
}

\begin{abstract}
The aim of this research was to study the effect of transformational leadership on employees' work outcomes which include their work performances and working burnout, and their working behavior such as social loafing at workplace. Also, it studies the impact of intrinsic motivation as a mediator between transformational leadership and other stated variables. A cross-sectional survey was conducted to collect data from 308 employees working in the telecommunication sector. To test the hypotheses, Model 4 of Process Hayes was used to test direct and mediating effects among transformational leadership and employees' work outcomes and working behavior. The results showed that transformational leadership has a significant positive relationship with mediator intrinsic motivation. The results also concluded that work performance has positive significant relationship with transformational leadership. However, there is indirect and insignificant relationship of transformational leadership with working burnout and social loafing. Therefore, it can be stated that organizational leaders must have transformational attributes by getting informed of their employees well because transformational leader can inspire employees to achieve anticipated or significant outcomes. It gives employees self-confidence over specific jobs, as well as the power to make decisions once they have been trained.
\end{abstract}

Keywords: Transformational leadership, Intrinsic motivation, Work performance, Working burnout, Social loafing

\section{Introduction}

During the last two decades, transformational leadership has gained most conspicuous place in philosophy of leadership [81]. Therefore, it is not surprising that the current evolution in leadership theory and practice has attracted the interest of both practitioners and researchers and they exhibited great deal of interest toward exploring its ascendancy for organization and individuals as well [72, 87]. Particularly, the studies conducted during the previous decades recommends that transformational leadership is considerably related to followers' behaviors and performance $[20,65]$. In a review on progress in the domain of leadership printed in "Annual Review of

\footnotetext{
*Correspondence: maryamrehmat@gmail.com

2 Department of Business Administration, Kinnaird College for Women,

Lahore, Pakistan

Full list of author information is available at the end of the article
}

Psychology," Avolio et al. [8] stressed the need to establish mechanisms that connect leadership to vital organizational and individual outcomes. They further stressed the need to investigate the role of mediators, so as to clarify the noteworthiness of leadership for organizations. Chan and Mak [20] in their research contended that "a variety of different influence processes may be involved in transformational leadership yet there is still room for research to further examine the process of the relationship between transformational leadership and follower attitudes and behaviors." Transformational leadership defined as leadership approach in which a leader transforms his followers, inspires them, builds trust, encourages them, admires their innovative ideas, and develops them [12], is presently the most extensively acknowledged definition in the leadership literature.

Transformational leadership can be implicated to managerial context. Transformational leadership which is the 
leader's competency to get performance of employees beyond expectations, can be more helpful and beneficial in enhancing one's ability to intrinsically motivate them. It can improve psychological empowerment as well [85]. Transformational leadership has four components which are: (i) idealized influence, (ii) inspirational motivation to enhance confidence, (iii) intellectual stimulation, and (iv) individualized consideration [13]. Idealized influence is shown when a leader efficiently makes provision of accurate sense of mission and appropriately visualizes it. Inspirational motivation can be defined as leadership attitude which deals with emotional traits of employees, builds confidence in employees about their performances, appropriately communicates and provides actual feedback [68]. Individual consideration refers to the support of leader for each follower. It may include training and coaching, allocating tasks according to the competence of each individual and supervision of performances [92]. Intellectual stimulation describes the effort of leader to motivate and encourage his employees to be more adaptive and follow new technical approaches according to the varied situation. It may be advantageous to overcome the cues and hindrances which occur at multi stages [14]. Transformational leaders can anticipate that employees will need transformational leadership when the work is more stressful and when the work is more meaningful [84].

Extant research on the transformational leadership tried to explore its "black box" and presented empirical confirmation of its direct fruitful consequences for followers' outcomes including work performance $[16,44$, $52,90]$, burnout [40, 82], and social loafing [5]. Nevertheless, there exists some room for further research, explaining the specific mechanisms by which transformational leadership influence such individuals' behavior and psychological state particularly at organizational level [16]. Hence, this study aims at providing new comprehension of how and why and under what circumstances transformational leadership influences work performance, burnout and social loafing of employees, in Pakistani context.

Transformational leadership tends to maximize the level of professional performance of work In addition to provided literature on association of transformational leadership and work performance; researchers indicate that organizations of diverse structures highly depend upon the performance of its workers. Past studies have empirically established the positive association between work performance and transformational leadership [9]. Transformational leaders inspire their followers to have shared vision of targeted goals and standards of performance defined by the organization and also facilitate them achieve it [4]. Another factor which is highly influenced by transformational leadership is employee's burnout which may be decreased through this particular style of leadership. Prevalence of stress is highly probable in any organizational sector [73]. Transformational leadership is most influencing factor which enhances the employee's ability to deal with all kind of circumstances as such leader provide supportive circumstances to employees so that they can maintain the optimum level of mental health through inspirational motivation and also enhances their confidence level $[28,93]$.

"Social loafing is the inclination of putting less effort while working in a team than working alone" [5]. Transformational leader, while working in a group, follows a strategy in which he can allocate various assignments and tasks according to the competencies of employee and he must evaluate performances of each individual. Social loafing is a psychological aspect of an individual which may differ from situation to situation and individual to individual [55]. Leadership literature has established that individualized consideration by the leader may deflate the degree of social loafing [45].

Building on the previous literature, this research incorporated employee intrinsic motivation as a factor that explains the linkage of transformational leadership with employee work performance, burnout and social loafing. Intrinsic motivation which is "the implementation of an action for the inherent satisfaction rather than for external reasons" [63]. Undeniably, the motivation of current workforce is not much reliant on extrinsic rewards. Rather material rewards may decline job performance in complex jobs with diverse responsibilities [30]. Further, in order to perform their duties effectively in today's dynamic work environment, the employees need to have an elastic and highly flexible work arrangement. For that reason and for instilling good motivation among workers, organizations not only offer extrinsic rewards to them but also plan to enhance their intrinsic motivation [63]. Transformational leadership is the leadership approach which contributes to present a clear and justified organizational vision and mission by motivating workers to work toward idea through developing association with employees, consider employees' requirements and assisting them to exert their potential positively, participates to positive outcomes for an organization [31]. Employees whose work competencies are encouraged by the leader are more likely to have higher intrinsic motivation and resultantly perform better at work. They become more focused and try to accomplish organizational goals by taking their own interests. There also exists indirect association between employees' burnout and transformational leadership through mediating effect of intrinsic motivation [28]. Transformational leaders focus more on individual requirements and they build strong association with their employees who are supposed to perform with 
higher objectives, which enhances employees' intrinsic motivation. Such motivation keeps them away from burning out [6]. We further argued that intrinsic motivation mediates the relationship between transformational leadership and social loafing. Previous studies indicate that role of intrinsic motivation discourages social loafing as it does not happen circumstantially only, but it also happens whenever an employee is low in intrinsic motivation [5].

This research makes provision of significant contribution in the literature of organizational behavior by enriching our understanding of the conditions under which transformational leadership influences employee performance, burnout and social loafing. The findings of our research allow organizations and its management to comprehend how efficiently and effectively they can follow a policy or some kind of advanced strategy in order to intrinsically motivate their employees so that they can increase the level of work performance and deflate burnout and social loafing in employees.

\section{Literature review}

\section{Transformational leadership and intrinsic motivation}

Envisioning visions and motivating are two core jobs of effective leadership [24]. According to traditional transformational leadership literature, transformational leaders guide and encourage employee mindfulness by enunciating a vision that escalates employees' consciousness and consideration for the significance of organizational values, goals, and performances [42]. Thusly, fundamental to the theory on transformational leadership is a strong accentuation on the part of a combined vision; that is, an idealized arrangement of objectives that the organization seeks to accomplish one day [18]. Transformational leaders, through clear enunciation, have their utmost influence on the followers' sentiments by cultivating a feeling of success and proficiency in them. Transformational leaders are much capable to improve organizational outcomes according to the market requirements by developing human resources and creating justified modifications [34]. The reason to acquire specific knowledge is associated with the degree that what is the level of intrinsic motivation of a person and how he is keen to get knowledge by developing particular competencies and meaningful learning [78]. Transformational leadership has power to enhance the ability of psychological empowerment which is referred as intrinsic motivation [85]. According to [74], the idea of motivation is known as "the set of reasons why people behave in the ways they do", for example, intrinsic motivation is "the motivational state in which the employees are driven by their interests in the work rather than a contract-forrewards approach to completing a task" [24]. A study by Koh et al. [51] identified that intrinsic motivation is highly influenced by the transformational leadership, as the transformational leader guides and supports effectively, self-motivation to be an effective and beneficial part of an organization increases as well.

Transformational leadership comprises four interconnected behavioral dimensions including "idealized influence, inspirational motivation, intellectual stimulation, and individualized consideration" [11]. All behavioral dimensions can influence employees' intrinsic motivation. First, transformational leaders utilize idealized influence and offer inspirational motivation through communicating an alluring collective vision [91]. This collective vision provides a meaningful idea of team's tasks by a leader which increase the intrinsic motivation of employees [75]. Transformational leadership can develop positive outcomes such as optimism and high self-interests in all members of team which ultimately increase the pleasure and job satisfaction relevant to the task [26]. Second, the intellectual stimulation of transformational leaders boosts team members' confidence to develop more effective emotional and situational stability and resolving their problems by their own selves [11]. They are also motivated to understand and encourage the basic knowledge and skills of other coworkers to share new ideologies. Third, transformational leaders differentiate individuals' ideas and interests, promote their ideas to describe their uniqueness, and consider them through individualized consideration [11]. When employees observe the behaviors of their leaders, all of them feel motivated and try to construct one another's ideas and competencies to create innovative solutions of problems. Therefore, in this article, we expect that all dimensions of transformational leadership encourage employees to invest higher willingness and energy in their work and tasks which exhibit their higher intrinsic motivation. Therefore, it can be hypothesized that:

$\mathbf{H}_{\mathbf{1}}$ Transformational leadership relates positively to intrinsic motivation.

\section{Transformational leadership, intrinsic motivation and work performance}

Intrinsic motivation is highly associated with the work performance. Intrinsic motivation may be defined as "the doing of an activity for its inherent satisfactions rather than for some separable consequence but it is rare for employees to experience intrinsic motivation in all of their tasks" [76]. Intrinsic motivation is generated for self-developing attributes that refers to make an individual ready to be the part of learning procedure without having interests of extrinsic rewards [83]. Intrinsic 
motivation is basically the degree of an individual's interest in a task completion and how he engages himself in work [3]. It describes the psychological development process with an employee's performance [85].

According to recent operational settings, enhancing the employees' motivation has become one of most impactful human resources strategy. Most of the organizations are tending to build up, sustain and grow their HR strategies, just to motivate their employees so that short-term and long-term goals and objectives can be achieved. In recent researches, there are numerous variables which can be influenced by employees' intrinsic motivation like performance, creativity, and relevant outcomes. For example, it has been stated that behavior of an individual influences the work outcomes which are performance and quality as well [10]. It is strongly evidenced that motivation has a most important role between cognitive abilities and work performance. Gist [37] suggested that short term goals can be achieved through self-interest of an individual. Also, a research indicates that there is a significant and direct relationship of intrinsic motivation and job performance [43]. Furthermore, an employee's intrinsic motivation illustrates an important contribution in organizational progress and growth [39]. The work performance indices are constructed for the degree of performance, not only for the individual level always; it also includes group and organizational performances [2]. In most employment situations, where intrinsic motivation of an employee is supposed to be high, the employee usually tries to acquire continual employment,and he/ she develops interpersonal associations with his subordinates, perform better at job as they take pleasure in the process of finishing their tasks effectively [38]. Conversely, if the worker feels de-motivated, it can be resulted in low performance of work. Thus intrinsic motivation may be concluded with better performance of work while meeting organizational targets and goals [7].

As we propose the direct relationship of intrinsic motivation and performance, it may be stated that the intrinsic motivation can actively influence the performance of work as a significant workplace outcome [19]. Therefore, we hypothesize that:

$\mathrm{H}_{2}$ Intrinsic motivation relates positively to employee work performance.

In current research, we posit that intrinsic motivation is one of the main mechanisms by which transformational leaders influence employees' job performance. Transformational leaders may help to ensure individual's inner motivation to perform a task efficiently which in turn increases their work performance .These leadership approaches are advantageous for both individual and organizational growth [36]. In fact, it is justified to examine how leaders motivate their employees and this motivation enhances their performance [12]. In line with the previous literature [22, 23], we expect that transformational leadership enhances individuals' intrinsic motivation which in turn will significantly predict employee job performance. Intrinsic motivation is known as selfdirected type of motivation and represents the highest commitment and stability with the self [25]. A variety of researches indicate that higher intrinsic motivation result in better performance [89] as intrinsic motivation inspires and encourages employees to work more efficiently. Therefore, it can be hypothesized:

$\mathbf{H}_{3}$ Intrinsic motivation mediates the relationship between transformational leadership and work performance.

\section{Transformational leadership, intrinsic motivation and employee's working burnout}

Intrinsically motivated employees persistently focus on their tasks and jobs because they find themselves more focused, attentive and exert their best efforts while being a part of an organization and in achieving the goals of their employing organization [76]. Burnout is a psychological and mental condition which happens in response to high stress level at job; it is a multi-dimensional concept which covers the following three aspects: emotional exhaustion, depersonalization, and decreased personal focus for accomplishment of goals [77]. Burnout affects the interpersonal relationship of employees too [58].

Prior research indicates that there is contrary effect of intrinsic motivation on employee's working burnout [70]. Intrinsically motivated employees find their jobs more interesting, are more optimistic, put more effort in their work, and have higher perseverance level because they gain contentment and fulfillment from performing a task itself [15]. Vallerand [88] in his study exhibit that "employees with high intrinsic motivation have higher level of vitality, positive effect, self-esteem, absorption, concentration, effort, and persistence" and when such employees went through the felling of burnout, they have more personal resources to surmount this situation. Such employees feel less exhausted, less stressed and more focused toward contributing in organization's progress [49]. Intrinsically motivated employees feel less pressure and low stress level rather than the employees who are low in motivation $[69,71]$. Intrinsic motivation of employees' can be negatively associated with their burnout [70].Therefore; the employees who are high in intrinsic motivation can decrease their burnout at workplace [50]. Thus, it can be hypothesized that: 
$\mathbf{H}_{4}$ Intrinsic motivation is negatively associated to employee's working burnout.

In current research, we propose that intrinsic motivation plays a mediating role between transformational leadership and burnout. Burnout is the major concern for organizations as it influences the relevant outcomes. It results in low productivity and commitment. Hence, it causes the high turnover and absenteeism in employees [82]. Studies indicate that leaders highly contribute to employees' health and welfare as well [80]. But the relationship between leadership behaviors and employee burnout is less studied yet [41]. As mentioned earlier, there exists a positive relationship between transformational leadership and intrinsic motivation which in turn make them more competent, teach them how to handle and manage stressful conditions and reduce their burnout. Therefore, we hypothesize that:

$\mathbf{H}_{5}$ Intrinsic motivation mediates the relationship of transformational leadership and employee's working burnout.

\section{Transformational leadership, intrinsic motivation and social loafing}

Social loafing is defined as the tendency of individuals who exert less effort and their productivity decreases when working in groups than working individually [21, $33,57,79]$. It is a negative employee behavior and is particularly shown by individuals with lower motivation [1]. These kinds of behaviors can be resulted in low productivity and poor commitment toward a task [62] and organization as well.

Social loafing is common practice and can be observed in every organizational setting, across age and gender and in different professions and various cultures [46]. This is more alarming that it can be seen at every single workplace and considered as misconduct. The variety of factors is studied in influence of social loafing, but there is still an insufficiency of individual inherent factors such as intrinsic motivation which is part of this research framework.

"Intrinsic motivation which describes an inherent tendency that individuals engage in activities due to their inner interests, pleasure and satisfaction" [70] is negatively linked to Social loafing. George [33] established in his study on 221 salespeople that intrinsic task involvement is negatively linked to social loafing. He further exerted that intrinsically motivated individuals may have self realization that their efforts are vital for the success of their team/group and for organization as well and therefore they are less likely to be engaged in social loafing.
$\mathrm{He} /$ she would try his/her own best to exert extra effort to accomplish the goals and tasks assigned by the leader.

Therefore, we hypothesize that:

$\mathbf{H}_{6}$ Intrinsic motivation is negatively linked to social loafing.

Intrinsic motivation may be described as the inherent process that initiates attributes, behaviors and what defines people to moves or act [27]. Self-determination theory indicates that there are different levels of motivation. Intrinsic motivation is at the most independent end of the scale because an individual opts to get engaged in any conduct according to his own choice [32]. A leader motivates his employees by incorporated strategies which results in better achievement of goals and objectives of a firm or organization. Gilbert et al. [35]. Social loafing is defined as a reduced amount of effort and motivation while being a part of group or working in a team as compared to working individually [46]. Social loafing is well-known phenomena and can be found in all of the organizations, across gender, and age and in various occupations and different cultures [46].

Social loafing is considered as a big hindrance in organizational growth as well. It causes low potential [61], low productivity [29], and low motivation of other team members too [67]. It decreases the overall efficiency, productivity and performance of the team [47]. Social loafing is widely spread term which is also known as social disease [54].

In line with this connection, social loafing is a big moral and social issue since it is an option that "involves modifying the life plan of another individual or group of individuals" [60]. On contrast, if a transformational leader motivates his employees and encourages their performance on individual basis, then through individualized considerations and inspirational motivation, social loafing can be decreased. Therefore, it can be hypothesized:

$\mathbf{H}_{7}$ Intrinsic motivation mediates the relationship of transformational leadership and social loafing.

\section{Mediating role of intrinsic motivation between transformational leadership and social loafing} (Fig. 1).

\section{Methods}

\section{Sample and data collection}

The data was collected through survey via emails, online surveys and printed questionnaires through convenience sampling from individuals working in the telecommunication sector. The participants were informed about the 


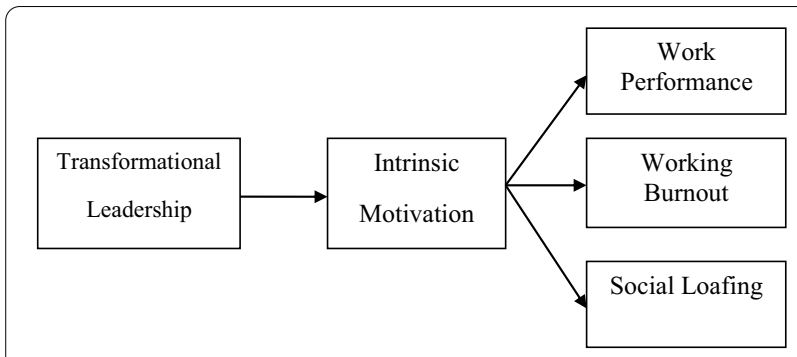

Fig. 1 Theoretical framework

Table 1 Frequency analysis of participants

\begin{tabular}{lcl}
\hline & Frequency & Percentage \\
\hline Gender & & \\
Male & 269 & 87.3 \\
Female & 39 & 12.7 \\
Age & & \\
$20-25$ & 2 & 0.6 \\
$26-30$ & 77 & 25.0 \\
$31-35$ & 81 & 26.3 \\
36-40 & 95 & 30.8 \\
Above 40 & 53 & 17.2 \\
Qualification & & \\
Diploma & 2 & 0.6 \\
Intermediate & 17 & 5.5 \\
Bachelors & 135 & 43.8 \\
Masters & 153 & 49.7 \\
Ph.D & 0 & 0 \\
\hline
\end{tabular}

objective of this study and the assurance of confidentiality and anonymity of their responses. Respondents were assured that their information will not be assessed by any individuals except those who are authorized. After removing the duplicates, outliers and responses with missing data, we obtained 308 valid responses for further data analysis Table 1 depicts the demographic characteristics of the respondents.

\section{Measures}

\section{Transformational leadership}

Transformational leadership was measured by McCollKennedy and Anderson [59] four-item scale. Six-point Likert scale (1-strongly disagree to 6-strongly agree) was used to measure responses. This is the most widely used scale to measure transformational leadership. Cronbach's alpha for transformational leadership scale is 0.84 .

\section{Intrinsic motivation}

In this study, Liu et al. [56] four-item scale was adopted to measure intrinsic motivation. To record the responses five-point Likert scale was used ( 1 - strongly disagree to 5-strongly agree). Cronbach's alpha for intrinsic motivation scale is 0.89 .

\section{Work performance}

To measure work performance [19] four-item scale was adopted. Five-point Likert scale (1-much worse to 5much better) was used to measure responses. Cronbach's alpha of work performance scale is 0.80 .

\section{Working burnout}

Working burnout was measured by Kristensen et al. [53]. Seven items with five-point Likert scale $(1$-never to 5always) was used. Cronbach's alpha of burnout scale is 0.88 .

\section{Social loafing}

Social loafing was measured by Akgunduz and Eryilmaz [1]. Four items with five-point Likert scale (1-strongly disagree to 5-strongly agree) was used. Cronbach's alpha of social loafing scale is 0.80 .

\section{Data analysis}

After data collection, the reliability, correlation was calculated by using SPSS software. Research model was tested using Hayes Process Model 4.

\section{Results}

\section{Descriptive statistics}

Table 2 describes descriptive statistics of all the study variables including the mean, standard deviation, and correlation. Correlation coefficients are in the anticipated directions and provide preliminary support for our study hypotheses. Our results depicts that transformational leadership and intrinsic motivation $(r=0.29, p<0.01)$ are positively and significantly correlated. Further intrinsic motivation is significantly associated with work performance $(r=.30, p<0.01)$; working burnout $(r=-0.59$, $p<0.01)$; social loafing $(r=-0.15, p<0.01)$.

\section{Reliability analysis}

To examine the consistency of the variables, reliability analysis is calculated. The reliabilities of all the variables with number of items are summarized in Table 3 . The values between 0.84 and 0.8 indicate good reliability. The reliability of transformational leadership is 0.84 which is good, and intrinsic motivation shows another good reliability which is 0.89 . Working burnout shows 0.88 reliability. The reliability of work performance is 0.8 and the reliability of social loafing is 0.8 which is also good. So this explains that the data used is reliable. 
Table 2 Mean, standard deviations and correlations

\begin{tabular}{|c|c|c|c|c|c|c|c|}
\hline Variables & Mean & SD & 1 & 2 & 3 & 4 & 5 \\
\hline 1. Transformational leadership & 4.44 & 1.00 & $(0.84)$ & & & & \\
\hline 2. Intrinsic motivation & 2.98 & 1.11 & $.29^{* *}$ & $(0.89)$ & & & \\
\hline 3. Working burnout & 3.25 & 0.97 & $-.20^{* *}$ & $-.59^{* *}$ & $(0.88)$ & & \\
\hline 4. Work performance & 3.95 & 0.76 & $.17^{* *}$ & $.30^{* *}$ & $-.24^{* *}$ & $(0.80)$ & \\
\hline 5. Social loafing & 1.87 & 0.68 & $-.48^{* *}$ & $-.15^{* *}$ & $.23^{* *}$ & $-.17^{* *}$ & $(0.80)$ \\
\hline
\end{tabular}

$N=308$; Cronbach's alpha (reliability coefficients) is on the diagonal in parentheses

${ }^{*} P<0.05 ;{ }^{* *} P<0.01$

Table 3 Reliability statistics

\begin{tabular}{lll}
\hline Scales & No. of items & $\begin{array}{l}\text { Cronbach's' } \\
\text { value }\end{array}$ \\
\hline 1. Transformational leadership & 4 & 0.842 \\
2. Intrinsic motivation & 4 & 0.893 \\
3. Working burnout & 7 & 0.877 \\
4. Work performance & 4 & 0.800 \\
5. Social loafing & 4 & 0.802 \\
\hline
\end{tabular}

Regression analysis

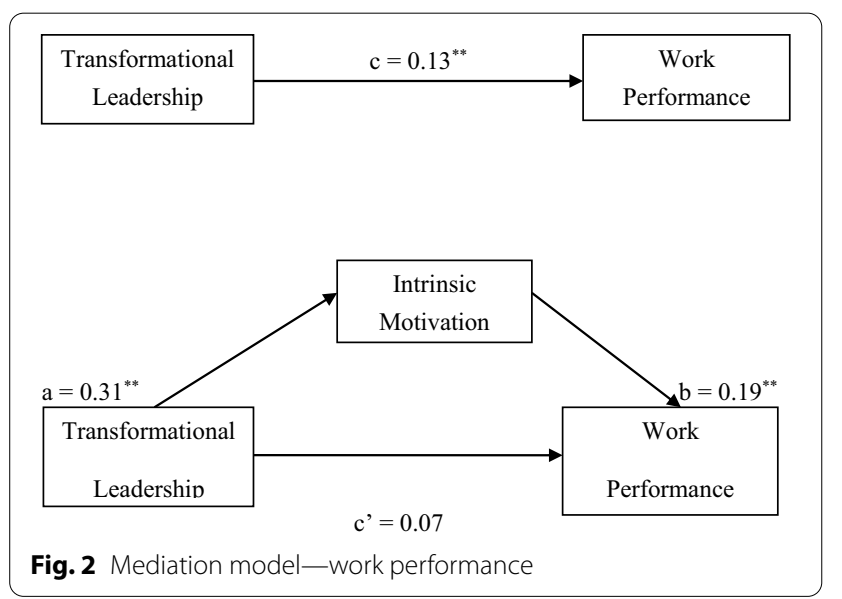

\section{Hypothesis testing}

\section{Results of mediation for work performance}

Firstly, we investigated the impact of Transformational Leadership (X) on Work Performance (Y) through mediating factor of Intrinsic Motivation (M). Results justify that total effect of transformational leadership on work performance (path c, Fig. 2) is significant $(\beta=0.13$, $t=3.07, p<0.01$ ) as shown in Table 4 . The relationship between transformational leadership and intrinsic motivation (path a, Fig. 4) is highly significant and positive which support Hypothesis 1 also $(\beta=0.31, t=5.20$, $p<0.01)$. Furthermore, the findings showed that the relationship between Intrinsic Motivation and Work
Performance (path b, Fig. 2) is positive and significant relationship ( $\beta=0.19, t=4.79, p<0.01)$.

Our overall findings represent that there is positive and significant impact of transformational leadership on work performance (path $c^{\prime}$, Fig. 2) through the mediation of intrinsic motivation $(\beta=0.07, t=1.68, p>0.01)$ which accepts Hypothesis 3.

\section{Results for mediation for working burnout}

In this model we studied the relationship of Transformational Leadership $(\mathrm{X})$ and Working Burnout $(\mathrm{Y})$ through mediating role Intrinsic Motivation (M). Results indicated that total effect of transformational leadership on working burnout is significant $(\beta=-0.19, t=-3.51$, $p<0.01$ We examined the relationship between the mediator, Intrinsic Motivation and the dependent variable, Working Burnout (path $b$, Fig. 3). The findings showed a significant and negative relationship $(\beta=-0.50$, $t=-11.98, p<0.01)$. This finding supports Hypothesis 4. As it is shown in Table 5 the final results determined a significant relationship between transformational leadership and working burnout with mediation of intrinsic motivation (path $c^{\prime}$, Fig. 3) $(\beta=-0.03, t=-0.66$, $p>0.01)$. Therefore Hypothesis 5 is accepted.

\section{Results for mediation for social loafing}

Our third and last finding for studied relationship between transformational leadership and social loafing through mediator intrinsic motivation, are presented in Table 6. According to the total effect model, the relationship between transformational leadership and social loafing (path $c$, Fig. 4) is significant and negative $(\beta=-0.32$, $t=-9.57, p<0.01)$ as shown in Table 6.

The outcomes showed that intrinsic motivation and social loafing (path $b$, Fig. 4) are insignificantly and related relationship $(\beta=-0.01, t=-0.31, p>0.01)$ which opposes Hypothesis 6.

Our last finding determined that transformational leadership does not have a significant negative impact on social loafing (path $c^{\prime}$, Fig. 3), while controlling intrinsic motivation $(\beta=-0.32, t=-9.07, p<0.01)$. Thus 
Table 4 Results of simple mediation model for work performance

\begin{tabular}{|c|c|c|c|c|c|}
\hline \multicolumn{6}{|l|}{ Direct effect model } \\
\hline \multirow[t]{2}{*}{ Predictor } & & \multicolumn{4}{|c|}{ Outcome = M (intrinsic motivation) } \\
\hline & & $\bar{\beta}$ & SE & $t$ & $p$ \\
\hline X (transformational leadership) & $a$ & 0.31 & 0.06 & 5.20 & 0.00 \\
\hline Constant & $i_{1}$ & 1.57 & 0.28 & 5.67 & 0.00 \\
\hline \multicolumn{6}{|l|}{ Direct effect model } \\
\hline \multirow[t]{2}{*}{ Predictor } & & \multicolumn{4}{|c|}{ Outcome $=\mathrm{Y}$ (work performance) } \\
\hline & & $\beta$ & SE & $t$ & $p$ \\
\hline X (transformational leadership) & $c^{\prime}$ & 0.07 & 0.04 & 1.68 & 0.09 \\
\hline M (intrinsic motivation) & $b$ & 0.19 & 0.04 & 4.79 & 0.00 \\
\hline Constant & $i_{2}$ & 3.07 & 0.19 & 15.41 & 0.00 \\
\hline \multicolumn{6}{|l|}{ Total effect model } \\
\hline \multirow[t]{2}{*}{ Predictor } & & \multicolumn{4}{|c|}{ Outcome $=Y$ (work performance) } \\
\hline & & $\beta$ & SE & $T$ & $p$ \\
\hline X (transformational leadership) & $c$ & 0.13 & 0.04 & 3.07 & 0.00 \\
\hline Constant & $i_{3}$ & 3.36 & 0.19 & 17.15 & 0.00 \\
\hline
\end{tabular}

$N=308 ; \mathrm{SE}=$ standard error; bootstrap sample size $=500$

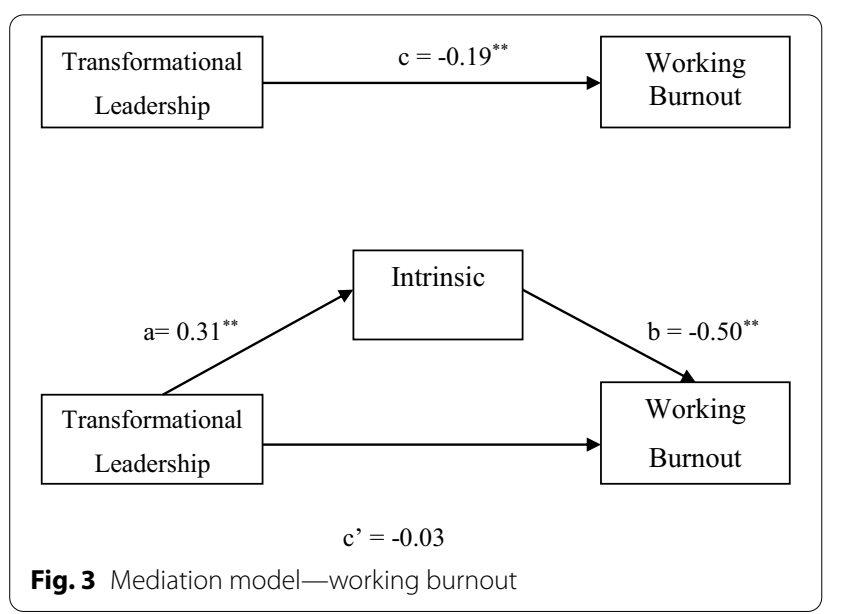

Hypothesis 7 is not accepted. Thus, it can be resulted that there is no mediation.

\section{Discussion}

\section{Theoretical contributions}

Although, previous researches have vastly recognized the direct impact of transformational leadership on positive employee work outcomes [17, 48], yet not all employees do not respond to transformational leadership optimistically [66]. This study overall, made an important contribution to the available literature mainly by including variables that are very essential for all work environments that are aiming toward high employee motivation and performance. The current study is a unique attempt to look at the relationship between of transformational leadership, employees' work performance, working burnout, and social loafing and intrinsic motivation in Asian context. This study contributes to the existing literature on transformational leadership since it is among the first to investigate the indirect impact of transformational leadership on employees' work performance, working burnout, and social loafing through intrinsic motivation. Providing empirical evidence for association between transformational leadership (independent variable), work performance, working burnout and social loafing (dependent variables) through the mediating effect of intrinsic motivation. Our empirical results provide support for our hypothesized model except for the indirect effect of transformational leadership on social loafing through intrinsic motivation. Transformational leadership consists of four elements which are idealized influence, inspirational motivation, intellectual stimulation and Individualized consideration [13]. All of these elements showed very good reliability and consistency with each other. These elements actively participate to affect the outcome of intrinsic motivation [85].

This study shows that transformational leadership has a significant and positive relationship with employees' intrinsic motivation. Previous literature supports this finding that transformational leadership promotes motivation in employees and develops positive psychological 
Table 5 Results of simple mediation model for working burnout

\begin{tabular}{|c|c|c|c|c|c|}
\hline \multicolumn{6}{|l|}{ Direct effect model } \\
\hline \multirow[t]{2}{*}{ Predictor } & & \multicolumn{4}{|c|}{ Outcome $=M$ (intrinsic motivation) } \\
\hline & & $\beta$ & SE & $t$ & $p$ \\
\hline X (transformational leadership) & $a$ & 0.31 & 0.06 & 5.20 & 0.00 \\
\hline Constant & $i_{1}$ & 1.57 & 0.28 & 5.67 & 0.00 \\
\hline \multicolumn{6}{|l|}{ Direct effect model } \\
\hline \multirow[t]{2}{*}{ Predictor } & & \multicolumn{4}{|c|}{ Outcome $=\mathrm{Y}$ (working burnout) } \\
\hline & & $\beta$ & SE & $t$ & $p$ \\
\hline X (transformational leadership) & $c^{\prime}$ & -0.03 & 0.04 & -0.66 & 0.50 \\
\hline M (intrinsic motivation) & $b$ & -0.50 & 0.04 & -11.98 & 0.00 \\
\hline Constant & $i_{2}$ & 4.90 & 0.21 & 22.75 & 0.00 \\
\hline \multicolumn{6}{|l|}{ Total effect model } \\
\hline \multirow[t]{2}{*}{ Predictor } & & \multicolumn{4}{|c|}{ Outcome $=\mathrm{Y}$ (working burnout) } \\
\hline & & $\beta$ & SE & $t$ & $p$ \\
\hline X (transformational leadership) & c & -0.19 & 0.05 & -3.51 & 0.00 \\
\hline Constant & $i_{3}$ & 4.10 & 0.24 & 16.55 & 0.00 \\
\hline
\end{tabular}

$N=308 ; \mathrm{SE}=$ standard error; bootstrap sample size $=5000$

Table 6 Results of simple mediation model for social loafing

Direct effect model

\begin{tabular}{|c|c|c|c|c|c|}
\hline \multirow[t]{2}{*}{ Predictor } & & \multicolumn{4}{|c|}{ Outcome = M (intrinsic motivation) } \\
\hline & & $\beta$ & SE & $t$ & $p$ \\
\hline X (transformational leadership) & $a$ & 0.31 & 0.06 & 5.20 & 0.00 \\
\hline Constant & $i_{1}$ & 1.57 & 0.28 & 5.67 & 0.00 \\
\hline \multicolumn{6}{|l|}{ Direct effect model } \\
\hline \multirow[t]{2}{*}{ Predictor } & & \multicolumn{4}{|c|}{ Outcome $=Y$ (social loafing) } \\
\hline & & $\beta$ & SE & $t$ & $p$ \\
\hline X (transformational leadership) & $c^{\prime}$ & -0.32 & 0.03 & -9.07 & 0.00 \\
\hline M (intrinsic motivation) & $b$ & -0.01 & 0.03 & -0.31 & 0.75 \\
\hline Constant & $i_{2}$ & 3.34 & 0.16 & 20.28 & 0.00 \\
\hline \multicolumn{6}{|l|}{ Total effect model } \\
\hline \multirow[t]{2}{*}{ Predictor } & & \multicolumn{4}{|c|}{ Outcome $=Y$ (social loafing) } \\
\hline & & $\bar{\beta}$ & SE & $t$ & $p$ \\
\hline X (transformational leadership) & $c$ & -0.32 & 0.03 & -9.57 & 0.00 \\
\hline Constant & $i_{3}$ & 3.33 & 0.15 & 21.25 & 0.00 \\
\hline
\end{tabular}

$N=308 ; \mathrm{SE}=$ standard error; bootstrap sample size $=5000$

states such as meaningfulness of work, experienced responsibility for the outcomes and knowledge of work results. It indicates that transformational leadership directly exerts its influence by helping employees or followers to think more positively about themselves and their tasks, by enhancing the quality of their relationships, and by creating environments that are fair, respectful, and supportive [86] and all of these factors contribute positively toward employee's self motivation toward his/ her work (i.e., intrinsic motivation). 



Fig. 4 Mediation model—social loafing

The positive elements of transformational leadership bring out positive psychological states by escalating intrinsic motivation among employees. Employees with increased intrinsic motivation are more effective and efficient toward their work performances. They are supposed to be converted into responsive and perform efficiently in their work [64].

This study results showed significant positive relationship of transformational leadership on working burnout through intrinsic motivation. When a transformational leader indicates support for honest and fair matters associated with employees, the employee feels less exhausted and motivated. Intrinsically motivated employees who are driven by enjoyment and interest in their work are more likely to work hard at their jobs and feel less fatigue, less emotional exhaustion, and increased desire to participate in the organization [49].

Finally, it was examined that how transformational leadership impact social loafing through Intrinsic motivation. Findings depicts that although Social loafing has a significant and negative relationship with transformational leader, but their indirect relationship through intrinsic motivation is not significant The reason behind can be that the direct strong association between transformational leader and social loafing as "transactional leaders effectively inspire followers to identify with a mission while rallying them to work together to achieve organizational objectives." Further, social loafing in employees is also effected significantly by other factors such as workload, organizational culture, tenure of job. etc.

\section{Practical implications}

Our study also provides several practical implications for organizations. Transformational leaders who realize the significance of intrinsic motivation for employees will adopt such behaviors that are conducive for development employees' intrinsic motivation at the workplace. The results of current study confirmed that transformational leadership through fostering intrinsic motivation create such environment which is stress free and fruitful for employee effective performance. One way to exhibit these behaviors by managers is to aim at encouraging motivation among employees based on their inherent happiness and enjoyment. Another way to enhance employees' intrinsic motivation and involvement toward organizational success is to value their contributions and sharing organizational goals and objectives with their workers. Further, it is very essential for organizational leaders to be transformed by being informed of their employees well because transformational leader can inspire people to achieve unexpected or remarkable results. It gives workers autonomy over specific jobs, as well as the authority to make decisions once they have been trained. In that the leader can inspire workers to find better ways of achieving a goal as leadership can mobilize people into groups that can get work done, and morale, in that transformational leaders raise the wellbeing and motivation level of a group through excellent connection. The findings of this study also stressed the need of designing leadership coaching and training programs in order to develop transformational leadership which may include "programs for communication, motivation, and brainstorming, to train employees with the necessary resources to be more articulate and inspirational as well as to think out of the box".

\section{Limitations and future directions}

The first limitation of this research is that cross-sectional survey has been conducted. There may be ambiguity in establishing causal direction. Results may vary while collecting data at various times. It is suggested to conduct longitudinal study design in future research to see how impact of transformational leadership on employee outcomes varies over time. Next, it represented data from only the telecom sector of Lahore, Pakistan which may limit the study generalizability it would have been advantageous to conduct this research across the diverse sectors and $\mathrm{n}$ different context. Another limitation of this research is that there can be a probability of response bias as all the data was collected through same source i.e., employees. For example, a person can have deliberate falsification by quoting false responses of statements, just to attain social desirability. An employee in the organization may have high degrees of social loafing but he may not state it appropriately as well. Future researchers may collect data from different sources like work performance data can be collected from supervisors. 
Existing literature and this research too is having high tendency toward constructive and significant outcomes to discover impact of transformational leadership so it is suggested that in future studies impact of transformational leadership should be examined in relation to more negative employee outcomes such as turnover intention and cyber loafing.

It is also recommended to see the impact of other mediators like emotional stability between transformational leadership and employees' various outcomes.

Furthermore, future studies can also observe the effect of different moderators such as performance appraisal politics and contingent awards on the existing research model. It might prove valuable.

Future studies can also respond to the limitations of current research by collecting data across different business sectors (education, banking, etc.) of diverse locations.

\section{Conclusion}

This research contributes to the field of organizational behavior by enhancing our knowledge on how a transformational leader upgrades employees' positive work outcomes by improving their intrinsic motivation. Furthermore, their increased intrinsic motivation will develop their positive work outcomes by increasing employees' work performance and the same time reducing their burnout and work stress. We hope that our study will stimulate future endeavors to advance our understanding in this domain.

\section{Acknowledgements}

We would like to thank family friends and teachers for their constant help and support to conduct this research.

\section{Authors' contribution}

Every author made contribution in each of the sections.HK completed her thesis on this topic for her M.Phil degree, MR supervised her in her thesis, THB has helped in proof reading the document and incorporating the reviewer's comments, SF helped in putting it into paper format and JA helped in the analysis. All the authors have read and approved the document.

\section{Funding}

This research did not receive any specific grant from funding agencies in the public, commercial, or not-for-profit sectors.

\section{Availability of data and materials}

The datasets used and/or analyzed during the current study are available from the corresponding author on reasonable request.

\section{Competing interest}

We do hereby solemnly affirm that we do not have any conflict of interest to declare, and that the study was conducted for purely academic/research purposes. "The authors have no competing interest."

\section{Author details}

${ }^{1}$ Kinnaird College for Women, Lahore, Pakistan. ${ }^{2}$ Department of Business Administration, Kinnaird College for Women, Lahore, Pakistan. ${ }^{3}$ School of Business Administration, National College of Business Administration and Economics, Lahore, Pakistan.
Received: 30 April 2020 Accepted: 2 November 2020

Published: 9 December 2020

\section{References}

1. Akgunduz Y, Eryilmaz G (2018) Does turnover intention mediate the effects of job insecurity and co-worker support on social loafing? Int J Hosp Manag 68:41-49

2. Aleksynska M (2018) Temporary employment, work quality, and job satisfaction. J Comp Econ 46(3):722-735

3. Ambrose ML, Kulik CT (1999) Old friends, new faces: motivation research in the 1990s. J Manag 25(3):231-292

4. Anderson HJ, Baur JE, Griffith JA, Buckley MR (2017) What works for you may not work for (Gen) Me: limitations of present leadership theories for the new generation. Leadersh Q 28(1):245-260

5. Arda ÖA, Yıldız B (2019) The moderating role of transformational leadership on the relationship between careerism and social loafing behaviors: a propositional review. In: Handbook of research on contemporary approaches in management and organizational strategy. IGI Global, pp 226-247

6. Arnold KA, Connelly CE, Gellatly IR, Walsh MM, Withey MJ (2017) Using a pattern-oriented approach to study leaders: implications for burnout and perceived role demand. J Organ Behav 38(7):1038-1056

7. Arnulf JK, Dysvik A, Larsen KR (2018) Measuring semantic components in training and motivation: a methodological introduction to the semantic theory of survey response. Hum Resour Dev Q 30:17-38

8. Avolio BJ, Walumbwa FO, WeberTJ (2009) Leadership: current theories, research, and future directions. Annu Rev Psychol 60:421-449

9. Barling J, Weber T, Kelloway EK (1996) Effects of transformational leadership training on attitudinal and financial outcomes: a field experiment. J Appl Psychol 81(6):827

10. Barrick MR, Parks L, Mount MK (2005) Self-monitoring as a moderator of the relationships between personality traits and performance. Pers Psychol 58(3):745-767

11. Bass BM, Riggio RE (2006) Transformational leadership, 2nd edn. Lawrence Erlbaum, Mahwah

12. Bass BM (1985) Leadership and performance beyond expectations. Collier Macmillan, London

13. Bass BM (1990) From transactional to transformational leadership: learning to share the vision. Org Dyn 18(3):19-31

14. Bednall TC, Rafferty AE, Shipton H, Sanders K, Jackson JC (2018) Innovative behaviour: how much transformational leadership do you need? Br J Manag 29(4):796-816

15. ten Brummelhuis LL, Ter Hoeven CL, Bakker AB, Peper B (2011) Breaking through the loss cycle of burnout: the role of motivation. J Occup Organ Psychol 84(2):268-287

16. Buil I, Martínez E, Matute J (2019) Transformational leadership and employee performance: the role of identification, engagement and proactive personality. Int J Hosp Manag 77:64-75

17. Burke CS, Sims DE, Lazzara EH, Salas E (2007) Trust in leadership: a multilevel review and integration. Leadersh Q 18(6):606-632

18. Carton AM, Murphy C, Clark JR (2014) A (blurry) vision of the future: how leader rhetoric about ultimate goals influences performance. Acad Manag J 57:1544-1570

19. Çetin F, Aşkun D (2018) The effect of occupational self-efficacy on work performance through intrinsic work motivation. Manag Res Rev 41(2):186-201

20. Chan SCH, MakWM (2014) Transformational leadership, pride in being a follower of the leader and organizational commitment. Leadersh Organ Dev J 35(8):674-690

21. Chang Y, Hou RJ, Wang K, Cui AP, Zhang CB (2020) Effects of intrinsic and extrinsic motivation on social loafing in online travel communities. Comput Hum Behav 109:106360

22. Charbonneau D, Barling J, Kelloway EK (2001) Transformational leadership and sports performance: the mediating role of intrinsic motivation 1. J Appl Soc Psychol 31(7):1521-1534

23. Conchie SM (2013) Transformational leadership, intrinsic motivation, and trust: a moderated-mediated model of workplace safety. J Occup Health Psychol 18(2):198 
24. Chen CHV, Li HH, Tang YY (2009) Transformational leadership and creativity: exploring the mediating effects of creative thinking and intrinsic motivation. Int J Manag Enterp Dev 6(2):198-211

25. Cox AE, Ullrich-French S, Tylka TL, McMahon AK (2019) The roles of self-compassion, body surveillance, and body appreciation in predicting intrinsic motivation for physical activity: cross-sectional associations, and prospective changes within a yoga context. Body Image 29:110-117

26. Deci EL, Ryan RM (1985) The general causality orientations scale: selfdetermination in personality. J Res Pers 19(2):109-134

27. Deci EL, Ryan RM (2008) Self-determination theory: a macrotheory of human motivation, development, and health. Can Psychol 49(3):182

28. Diebig M, Bormann KC, Rowold J (2017) Day-level transformational leadership and followers' daily level of stress: a moderated mediation model of team cooperation, role conflict, and type of communication. Eur J Work Organ Psychol 26(2):234-249

29. Duffy MK, Shaw JD (2000) The Salieri syndrome: consequences of envy in groups. Small Group Res 31(1):3-23

30. Erez M, Gopher D, Arzi N (1990) Effects of goal difficulty, self-set goals, and monetary rewards on dual task performance. Organ Behav Hum Decis Process 47(2):247-269

31. Fitzgerald S, Schutte NS (2010) Increasing transformational leadership through enhancing self-efficacy. J Manag Dev 29(5):495-505

32. Gagné M, Deci EL (2005) Self-determination theory and work motivation. J Organ Behav 26(4):331-362

33. George JM (1992) Extrinsic and intrinsic origins of perceived social loafing in organizations. Acad Manag J 35(1):191-202

34. Ghasabeh MS, Soosay C, Reaiche C (2015) The emerging role of transformational leadership. J Dev Areas 49(6):459-467

35. Gilbert S, Horsman P, Kelloway EK (2016) The motivation for transformational leadership scale. Leadersh Organ Dev J 49(6):459-467

36. Gillet N, Fouquereau E, Bonnaud-Antignac A, Mokounkolo R, Colombat $P$ (2013) The mediating role of organizational justice in the relationship between transformational leadership and nurses' quality of work life: a cross-sectional questionnaire survey. Int J Nurs Stud 50(10):1359-1367

37. Gist ME (1987) Self-efficacy: implications for organizational behavior and human resource management. Acad Manag Rev 12(3):472-485

38. Grant AM (2008) Does intrinsic motivation fuel the prosocial fire? motivational synergy in predicting persistence, performance, and productivity. J Appl Psychol 93(1):48

39. Gumusluoglu L, Ilsev A (2009) Transformational leadership, creativity, and organizational innovation. J Bus Res 62(4):461-473. https://doi. org/10.1016/j.jbusres.2007.07.032

40. Hildenbrand K, Sacramento CA, Binnewies C (2018) Transformational leadership and burnout: the role of thriving and followers' openness to experience. J Occup Health Psychol 23(1):31

41. De Hoogh AH, Den Hartog DN (2009) Neuroticism and locus of control as moderators of the relationships of charismatic and autocratic leadership with burnout. J Appl Psychol 94(4):1058

42. Jensen UT, Bro LL (2018) How transformational leadership supports intrinsic motivation and public service motivation: the mediating role of basic need satisfaction. Am Rev Pub Admin 48(6):535-549

43. Joo BKB, Park S (2010) Career satisfaction, organizational commitment, and turnover intention. Leadersh Organ Dev J 31 (6):482-500

44. Judge TA, Piccolo RF (2004) Transformational and transactional leadership: a metaanalytic test of their relative validity. J Appl Psychol 89(5):755-768

45. Kahai SS, Sosik JJ, Avolio BJ (2003) Effects of leadership style, anonymity, and rewards on creativity-relevant processes and outcomes in an electronic meeting system context. Leadersh Q 14(4-5):499-524

46. Karau SJ, Williams KD (1993) Social loafing: a meta-analytic review and theoretical integration. J Pers Soc Psychol 65(4):681

47. Karau SJ, Williams KD (1995) Social loafing: research findings, implications, and future directions. Curr Dir Psychol Sci 4(5):134-140

48. Khattak MN, Zolin R, Muhammad N (2020) Linking transformational leadership and continuous improvement. Manag Res Rev 43(8):931-950

49. Kim S (2017) National culture and public service motivation: investigating the relationship using Hofstede's five cultural dimensions. Int Rev Admin Sci 83(1):23-40

50. Kim J (2018) The contrary effects of intrinsic and extrinsic motivations on burnout and turnover intention in the public sector. Int J Manpow 39(3):486-500
51. Koh D, Lee K, Joshi K (2019) Transformational leadership and creativity: a meta-analytic review and identification of an integrated model. J Organ Behav 40(6):625-650

52. Kovjanic S, Schuh SC, Jonas K (2013) Transformational leadership and performance: an experimental investigation of the mediating effects of basic needs satisfaction and work engagement. J Occup Organ Psychol 86(4):543-555

53. Kristensen TS, Borritz M, Villadsen E, Christensen KB (2005) The copenhagen burnout inventory: a new tool for the assessment of burnout. Work \& Stress 19(3):192-207

54. Latane B, Williams K, Harkins S (1979) Social loafing. Psychol Today 110:104-106

55. Liden RC, Wayne SJ, Jaworski RA, Bennett N (2004) Social loafing: a field investigation. J Manag 30(2):285-304

56. Liu Y, Raker JR, Lewis JE (2018) Evaluating student motivation in organic chemistry courses: moving from a lecture-based to a flipped approach with peer-led team learning. Chem Educ Res Pract 19(1):251-264

57. Luo Z, Qu H, Marnburg E (2013) Justice perceptions and drives of hotel employee social loafing behavior. Int J Hosp Manag 33:456-464

58. Maslach C (2003) Job burnout: new directions in research and intervention. Curr Dir Psychol Sci 12(5):189-192

59. McColl-Kennedy JR, Anderson RD (2002) Impact of leadership style and emotions on subordinate performance. Leadersh Q 13(5):545-559

60. Mihelič KK, Culiberg B (2019) Reaping the fruits of another's labor: the role of moral meaningfulness, mindfulness, and motivation in social loafing. J Bus Ethics 160(3):713-727

61. Monzani L, Ripoll P, Peiró JM, Van Dick R (2014) Loafing in the digital age: the role of computer mediated communication in the relation between perceived loafing and group affective outcomes. Comput Hum Behav 33:279-285

62. Mulvey PW, Klein HJ (1998) The impact of perceived loafing and collective efficacy on group goal processes and group performance. Organ Behav Hum Decis Process 74(1):62-87

63. Nguyen HM, Mai LT, Huynh TL (2019) The role of transformational leadership toward work performance through intrinsic motivation: a study in the Pharmaceutical field in Vietnam. J Asian Finance Econ Bus 6(4):201-212

64. Panatik SAB, Badri SKZ, Rajab A, Rahman HA, Shah IM (2011) The impact of work family conflict on psychological well-being among school teachers in Malaysia. Proc Soc Behav Sci 29:1500-1507

65. Piccolo RF, Colquitt JA (2006) Transformational leadership and job behaviors: the mediating role of core job characteristics. Acad Manag J 49(2):327-340

66. Porter LW, Bigley GA (2003) Motivation and transformational leadership: Some organizational context issues. In: Allen RW, Porter LW, Angle HL (eds) Organizational influence processes. Routledge, New York, pp 263-274

67. Price KH, Harrison DA, Gavin JH (2006) Withholding inputs in team contexts: member composition, interaction processes, evaluation structure, and social loafing. J Appl Psychol 91(6):1375-1384

68. Rafferty AE, Griffin MA (2004) Dimensions of transformational leadership: conceptual and empirical extensions. Leadersh Q 15(3):329-354

69. Robbins S, Judge T (2014) Comportements organisationnels. Pearson Education

70. Ryan RM, Deci EL (2000) Intrinsic and extrinsic motivations: classic definitions and new directions. Contemp Educ Psychol 25(1):54-67

71. Schaufeli WB, Leiter MP, Maslach C (2009) Burnout: 35 years of research and practice. Career Dev Int 14(3):204-220

72. Sahu S, Pathardikar A, Kumar A (2018) Transformational leadership and turnover: mediating effects of employee engagement, employer branding, and psychological attachment. Leadersh Organ Dev J 39(31):82-99. https://doi.org/10.1108/LODJ-12-2014-0243

73. Saleem S, Ali A, Akhtar I (2016) Impact of transformational leadership on job stress and burnout: the mediating role of self-efficacy. Int J Univ Teknol Malaysia 1-16

74. Santrock JW (2002) Life-span development, 8th edn. McGraw-Hill

75. Shamir B, House RJ, Arthur MB (1993) The motivational effects of charismatic leadership: a self-concept based theory. Organ Sci 4(4):577-594

76. Shin J, Grant AM (2019) Bored by interest: how intrinsic motivation in one task can reduce performance on other tasks. Acad Manag J 62(2):415-436 
77. Shoshan HN, Venz L, \& Sonnentag S (2019, July) Being recovered as an antecedent of emotional labor: a diary study. In: Academy of management proceedings, vol. 2019, no. 1. Academy of Management, Briarcliff Manor, p 14363

78. Silva WF, Redondo RP, Cárdenas MJ (2018) Intrinsic motivation and its association with cognitive, actitudinal and previous knowledge processes in engineering students. Contemp Engin Sci. https://doi.org/10.12988/ CES.2018.79114

79. Simms A, Nichols T (2014) Social loafing: a review of the literature. J Manag Policy Pract 15(1):58

80. Skakon J, Nielsen K, Borg V, Guzman J (2010) Are leaders' well-being, behaviours and style associated with the affective well-being of their employees? A systematic review of three decades of research. Work Stress 24(2):107-139

81. Sosik JJ, Jung D (2018) Intellectual stimulation: the rational side of transformational leadership. In: Full range leadership development. Routledge, pp 132-158

82. Tafvelin S, Nielsen K, von Thiele Schwarz U, Stenling A (2019) Leading well is a matter of resources: leader vigour and peer support augments the relationship between transformational leadership and burnout. Work Stress 33(2):156-172

83. Tanneberg D, Peters J, Rueckert E (2019) Intrinsic motivation and mental replay enable efficient online adaptation in stochastic recurrent networks. Neural Netw 109:67-80

84. Tepper BJ, Dimotakis N, Lambert LS, Koopman J, Matta FK, Man Park H, Goo W (2018) Examining follower responses to transformational leadership from a dynamic, person-environment fit perspective. Acad Manag 61(4):1343-1368

85. Thomas KW, Velthouse BA (1990) Cognitive elements of empowerment: an "interpretive" model of intrinsic task motivation. Acad Manag Rev 15(4):666-681
86. Turnnidge J, Côté J (2017) Transformational coaching workshop: applying a person-centred approach to coach development programs. Int Sport Coach J 4(3):314-325

87. Udin U (2020) Transformational leadership and organizational citizenship behavior: an empirical investigation. Revista ESPACIOS 41(01)

88. Vallerand IA (2017) Burnout among MD/PhD trainees: the forgotten subgroup. Acad Med 92(7):906

89. Vanstraelen A (2019) Discussion of "how does intrinsic motivation improve auditor judgment in complex audit tasks?". Contemp Account Res 36(1):132-138

90. Walumbwa FO, Hartnell CA (2011) Understanding transformational leadership-employee performance links: the role of relational identification and self-efficacy. J Occup Organ Psychol 84(1):153-172

91. Wang XHF, Kim TY, Lee DR (2016) Cognitive diversity and team creativity: effects of team intrinsic motivation and transformational leadership. J Bus Res 69(9):3231-3239

92. Yukl G (1999) An evaluation of conceptual weaknesses in transformational and charismatic leadership theories. Leadersh Q 10(2):285-305

93. Zwingmann I, Wegge J, Wolf S, Rudolf M, Schmidt M, Richter P (2014) Is transformational leadership healthy for employees? A multilevel analysis in 16 nations. German J Hum Resour Manag 28(1-2):24-51

\section{Publisher's Note}

Springer Nature remains neutral with regard to jurisdictional claims in published maps and institutional affiliations.

\section{Submit your manuscript to a SpringerOpen ${ }^{\circ}$ journal and benefit from:}

- Convenient online submission

- Rigorous peer review

- Open access: articles freely available online

- High visibility within the field

- Retaining the copyright to your article

Submit your next manuscript at $\boldsymbol{\nabla}$ springeropen.com 